\section{The development of concepts of}

\section{numerical magnitude*}

\author{
LINDA S. SIEGEL \\ McMaster University, Hamilton, Ont., Canada
}

The sequence of development of several magnitude concepts was studied in 72 children ranging in age from 3 years and 0 months to 4 years and 11 months. The ability to understand the concept of oneness develops concurrently with the ability to discriminate relative numerical magnitude with stimuli of similar densities (linear magnitude). Discrimination of numerical magnitude in which the spatial and length cues to the numerical size of the group are minimized (nonlinear magnitude) was found to be significantly more difficult than either the oneness or linear magnitude discrimination.

One of the most elementary quantitative concepts is that of relative numerical magnitude, i.e., the recognition that two sets of objects differ in number, with one set having more or fewer objects than another set has. In a study of the development of numerical concepts in young children, Siegel (1971) found that the relative magnitude concept, involving comparisons of sets of different numbers of dots, was one of the earliest number concepts to be understood by children and that this concept of greater and lesser magnitude developed in young children between the ages of 3 and 4 .

The stimuli used in this magnitude task, called here the linear magnitude task, were groups of dots of equivalent densities but of different numerical size and length. Since spatial cues play an important role in children's perceptions of numerosity (e.g., Piaget, 1965; Wohlwill, 1960), the purpose of the present study was to assess children's ability to discriminate relative magnitude when there were no length cues to the size of the set. A task, called nonlinear magnitude, in which the stimuli of different numerical magnitudes consisted of dots arranged in random patterns of approximately equal areas, tested the development of the magnitude concept with minimal spatial cues to set size. The present study tested the hypothesis that the concept of relative magnitude should develop first with linear arrays, where there are spatial cues to the size of the set, and later

* This research was supported by Medical Research Council of Canada Grant MA-3773. The author wishes to thank the following people for their cooperation in providing $S s$ for the study: Rabbi Weinberger of the Hamilton Hebrew Academy, Mrs. L. Raftery of the Little Mountaineers Nursery, Mr. and Mrs. Ressel of the Ressel Day Nursery, and Mr. J. Kormos of the Brant Pre-School. The author also wishes to thank Mrs. Sophie Berenbaum, Miss June Cunningham, and Mrs. Anne Wysmyk for their assistance in the data collection and analysis. with nonlinear or random arrangements of objects in which the spatial cues to numerical magnitude have been eliminated.

The absolute size of the numerical array may be a factor in magnitude discriminations. Previous studies, such as those of IIg \& Ames (1951), found that children as young as 2 years had the ability to distinguish a single unit or one object from more than one or many objects. This concept of oneness would appear to be the simplest magnitude concept, and the present study also tested the hypothesis that the development of the concept of oneness precedes the development of other magnitude concepts.

The tasks used to test the development of these magnitude concepts in young children were complex relational discriminations in which the child was reinforced for choosing the smaller or larger group of objects whose absolute numbers varied from trial to trial. Nonverbal methods were used to assess these concepts, because studies such as those of Braine (1959) and Siegel \& Goldstein (1969) have shown that reliance on language to measure the development of quantitative concepts in young children can be misleading.

\section{SUBJECTS}

The Ss were 72 children, ranging in age from 3 years and 0 months $(3 / 0)$ to 4 years and 11 months (4/11) at the time of testing, from nursery schools in Hamilton and Burlington, Ontario. The majority of the children were from middle class backgrounds. There were 18 children at each of four age levels: $3 / 0-3 / 5,3 / 6-3 / 11,4 / 0-4 / 5$, and 4/6-4/11. Within each age group, there were three subgroups, each composed of 3 girls and 3 boys, who received the experimental treatments described below.

\section{DESIGN AND PROCEDURE}

Each $S$ was administered three tasks on a two-choice discrimination learning apparatus in which the stimuli were presented on slides and the child was required to respond by pressing a button associated with either one of the two pictures that appeared on the screen. The two buttons were located directly below the stimuli, each of which had a projected size of approximately $3 \times 4$ in. The correct response was reinforced with a small candy (Smartie). A noncorrection procedure was used; after any response, correct or incorrect, the machine advanced to the next trial. For all tasks, the left-right position of the correct alternative varied randomly from trial to trial. There were three subgroups within each age level; each third of the Ss at each age level was administered a different order of the three tasks in a Latin square design.

Each child was tested individually. The criterion for all tasks was 9 out of 10 consecutive correct responses; if the child failed to reach criterion in 48 trials, the task was terminated. TASKS

The three tasks were as follows: Oneness

The stimuli for this task were eight pairs of numbers, representing comparisons between the number 1 and the numbers 2 through 9 (e.g., $1-2,1-3,1-4,1-5,1-6,1-7,1-8,1-9)$. The numbers were represented by black dots in a vertical linear array. The vertical arrays were of the same density.

\section{Linear Magnitude}

The stimuli for this task were eight pairs of numbers, $2-5,3-5,3-6,4-6$, $4-7,5-8,6-8,6-9$, in which the dots representing the numbers were arranged in linear vertical arrays of equal density.

\section{Nonlinear Magnitude}

The stimuli for this task were the same eight pairs of numbers used in the linear magnitude task. The dots representing the numbers were arranged in a random pattern of approximately equal areas.

For each task, the eight stimuli were presented six times, with counterbalanced position of the correct answer, for a total of 48 trials for each task. Half the Ss were reinforced for choosing the larger magnitude and the other half, for choosing the smaller magnitude.

\section{RESULTS}

The mean number of trials to criterion for the three tasks for each age group is shown in Fig. 1. The children who failed to reach criterion on a particular task were assigned a score of 48 . A Latin-square analysis was performed on these data; there were significant effects of age $(F=$ 11.97, df $=3,60, p<.001$ ) and task $(\mathrm{F}=36.54, \mathrm{df}=2,120, \mathrm{p}<.001)$ and a significant Age by Task interaction $(F=2.17, \mathrm{df}=6,120, \mathrm{p}<.05)$. There were no significant effects of order or 


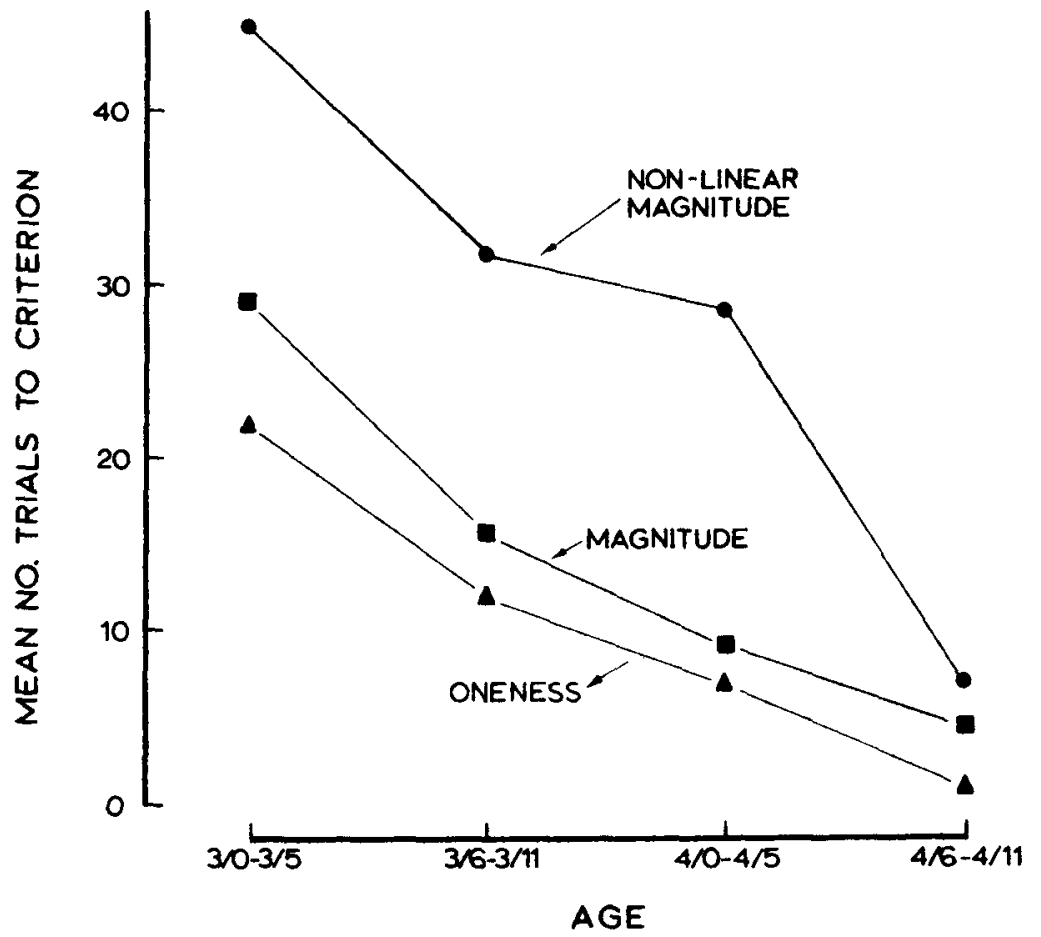

Fig. 1. Mean number of trials to criterion as a function of age and task.

significant interactions of order with age or task. Individual comparisons of the means for each age group on each task were made using the Duncan multiple-range test. Although the oneness task was not significantly easier than the magnitude task, the nonlinear magnitude was significantly more difficult than the simple magnitude one for all age groups except the oldest one.

To determine the extent to which this sequence represents a meaningful developmental sequence, the scalogram analysis discribed in Green (1954) was used. The scalogram for the tasks in the hypothesized order of difficulty (oneness, magnitude, nonlinear magnitude) was .98. The concept of oneness and simple magnitude appear to develop concurrently, since only $8.3 \%$ of the Ss failed the magnitude and passed the oneness task. The simple magnitude concept clearly develops before the nonlinear magnitude, in that $27.8 \%$ (35.2\% if the oldest age group is excluded) passed the simple magnitude and failed the nonlinear magnitude task.

\section{DISCUSSION}

According to the results of this study, children develop the concept of relative magnitude earlier when the comparisons include spatial cues to the size of the array than they do when these cues are removed. The nonlinear magnitude task used in this study removes the spatial and length cues to the size of the group that Gelman (1969) found that children use in discriminating numbers. The findings of this study indicate that initially the child discriminates magnitude on the basis of length, since the removal of length cues to the size of the set makes discrimination of magnitude significantly more difficult.

\section{REFERENCES}

BRAINE, M. D. S. The ontogeny of certain logical operations: Piaget's formulation examined by nonverbal methods. Psychological Monographs, 1959, 73(5, Whole No, 475).

GELMAN, R. Conservation acquisition: A problem of learning to attend to relevant attributes. Joumal of Experimental Child Psychology, 1969, 7, 167-187.

GREEN, B. F. Attitude measurement. In G. Lindzey (Ed.), Handbook of social psychology. Vol. 1, Cambrdige, Mass: Addison-Wesley, 1954.

ILG, F.. \& AMES, L. B. Developmental trends in arithmetic. Journal of Genetic Psychology, 1951, 79, 3-28.

PIAGET, J. The child's conception of number. New York: Norton, 1965.

SIEGEL, L. S. The sequence of development of certain number concepts in preschool children. Developmental Psychology, 1971, 5, 357-363.

SIEGEL, L. S., \& GOLDSTEIN, A. G. Conservation of number in young children: Recency versus relational response strategies. Developmental Psychology, 1969, 1, 128-130.

WOHLWILL, J. F. A study of the development of the number concept by scalogram analysis. Journal of Genetic Psychology, 1960, 97, 345-77. 